\title{
Article \\ Interaction and Grammar: Predicative Adjective Constructions in English Conversation
}

\author{
Joan Bybee ${ }^{1, *}$ and Sandra A. Thompson ${ }^{2}$ (D) \\ 1 Department of Linguistics, University of New Mexico, Albuquerque, NM 87131-0001, USA \\ 2 Department of Linguistics, University of California, Santa Barbara, Santa Barbara, CA 93106-3100, USA; \\ sathomps@linguistics.ucsb.edu \\ * Correspondence: joan.bybee@gmail.com
}

check for updates

Citation: Bybee, Joan, and Sandra A. Thompson. 2022. Interaction and Grammar: Predicative Adjective Constructions in English Conversation. Languages 7: 2. https://doi.org/10.3390/ languages7010002

Academic Editors: Esther L. Brown Javier Rivas, Juana M. Liceras and Raquel Fernández Fuertes

Received: 22 May 2021

Accepted: 14 December 2021

Published: 27 December 2021

Publisher's Note: MDPI stays neutral with regard to jurisdictional claims in published maps and institutional affiliations.

Copyright: () 2021 by the authors Licensee MDPI, Basel, Switzerland. This article is an open access article distributed under the terms and conditions of the Creative Commons Attribution (CC BY) license (https:// creativecommons.org/licenses/by/ $4.0 /)$.

\begin{abstract}
This article studies the function of Copular Predicate Constructions in everyday English conversation. We compare predicate adjective constructions (PA) and constructions with a predicate nominal containing an adjective (PAN). We ask whether the attributive function of the adjective or the presence of a noun in the PAN leads to a difference in function in the two constructions. We propose that in most cases the adjective determines the function of the construction, leading to many parallels in usage between the PA and PAN constructions. A comparison with predicate nominal constructions (PN), in contrast, shows that not including an adjective in the constructions leads to a different set of meanings and implications. The conversational usage of these constructions provides evidence for a partial correspondence of form to function: Copular Predicate Constructions often constitute a complete turn in conversation, and if not a full turn, form their own prosodic units. Other properties of these constructions - the definiteness of the NP and the presence or absence of a $\mathrm{N}$-correspond to different interactional work. A comparison of all three constructions shows that the adjective plays a determining interactional role, despite differences in syntactic configuration.
\end{abstract}

Keywords: Copular Construction; predicate adjective; predicate nominal; copula

\section{Introduction}

Clauses with non-verbal predicates have long been of interest in functional and typological linguistics (e.g., Hengeveld 1992; Overall et al. 2018; Dixon [1970] 2010; Narahara 2002; Clements 2006). In the context of the current Special Issue, we would like to ask how the structure and content of these clauses relate to the role they play in conversation. This article addresses this question by considering a pair of English constructions built around the copula, those in which the predicate is an Adjective (the Predicate Adjective construction, or PA) or an Adjective + Noun (the Predicate Adjective Noun construction, or PAN). ${ }^{1}$ Focusing on these two constructions highlights the traditional distinction between the attributive and predicative roles that adjectives can play in a clause, as the PA is predicative and the adjective within the PAN is in an attributive construction. For comparison, we will also draw on a set of Predicate Nominal constructions (PNs). We will refer to the three constructions together as 'Copular Predicate Constructions'; they are all built as clauses with the form [NP Copula PA/PAN/PN]. These are illustrated, respectively, in these extracts: ${ }^{2}$

(1) PA I was miserable ${ }^{3}$

(2) PAN it was atypical weather

(3) PAN it was really a treat.

The attributive-predicative distinction has been noted with interest by traditional and functional linguists and grammarians (Quirk et al. 1985, pp. 402-3; Thompson 1988; Englebretson 1997; Biber et al. 1999; Clements 2006; Ono and Thompson 2009; Thompson and Tao 2010; Bybee and Napoleão de Souza 2019). For English, an attributive adjective is 
generally understood to "premodify a noun" (Quirk et al. 1985, p. 402) in the same noun phrase (NP), while predicate adjectives predicate a property of the clausal subject. We are especially interested, then, in the PAN construction, where the adjective can be argued to be playing both roles: it premodifies a noun in an NP, but that NP is doing predicate work in its clause.

The functions served by PAs and PANs in language use has, to the best of our knowledge, never been investigated. We will demonstrate that these constructions serve to do specific interactional jobs, and, as might be expected, PAs and PANs are similar to each other in some respects and different in others. In particular, we hypothesize that the properties of adjectives influence the interactional work of these constructions. As often noted, adjectives are gradable and take degree modifiers (Quirk et al. 1985, p. 402-3; Huddleston and Pullum 2002, p. 528). The interpretation of the meaning of an adjective depends upon an implicit standard of comparison, which changes according to the context. This variability allows for a degree of subjectivity in the use of adjectives by speakers. We argue that the lexical meaning of the adjective is an important determinant of the interactional work accomplished by the Predicate Copula Constructions.

As Schegloff (1996b) has pointed out, it is in interactional settings that we can see grammar 'at work', and can thus begin to appreciate what 'grammar' must be understood to be. We thus seek to answer, for the first time, these questions:

- What interactional work do speakers use PAs and PANs for, and to what extent are these two constructions used to do similar work?

- What is the role of the $\mathrm{N}$ and what is the role of the $\mathrm{A}$ in determining the way the constructions are used in conversation?

- In the PAN construction, is the A doing the work of an attributive, or a predicative, adjective?

- From a purely syntactic point of view, PN and PAN should be the same construction: $[\mathrm{NP}+\mathrm{COP}+\mathrm{NP}]$. How similar do they turn out to be in function?

The analysis reported here is based on these questions and does not test any specific hypotheses. Even though this study is based on a large number of naturally occurring examples that indicate certain trends, it is intended to be qualitative- that is, aimed towards deepening our understanding of the social function of PAs and PANs in everyday conversation.

The paper is organized as follows: Section 2 outlines our data and methods, and Section 3, the relative distribution of the constructions in our data. In Sections 4-8, we present our analyses. Section 9 returns to the question of role of the Adjective vis-a-vis the Noun in our target constructions, and Section 10 explores the theoretical implications of our study.

\section{The Data and Method}

Our data are drawn from video and telephone audio recorded conversations among American English-speaking friends and family members. We chose these data sets as typical of the conversations we have studied over the past several decades. We manually searched the CALLFRIEND data archive $\mathrm{e}^{4}$ in addition to about $40 \mathrm{~h}$ of our own and colleagues' datasets, in which the participants were simply interacting normally in various informal interactional settings with no instructions from the researchers setting up the recording. All interactions were recorded with permission, and transcribed by trained transcribers.

From the telephone conversations in the Call Friend data archive, we manually extracted all PANs from seven conversations among sixteen speakers, totaling over 60,000 words. Because PAs are more frequent than PANs (see Section 3), all PAs were extracted from four conversations plus the first 1000 lines from a fifth one, totaling approximately 30,000 words. From our own datasets, we examined 16 conversations, of which 12 were face-to-face, and 4 were phone calls. These totaled $6.5 \mathrm{~h}$ of talk among two to six speakers each, and comprised roughly 110,000 words. Again, we manually extracted all the PAs from eight conversations, and all the PANs from the first 2000 words of the other eight. We collected instances from both sets of conversations until we had 150 PAs and 75 PANs. For 
comparison, we also collected all the PNs from our own datasets until we had 70 in total. Table 1 shows these totals.

Table 1. Numbers of PA, PAN, and PN constructions.

\begin{tabular}{ccccc}
\hline & PA & PAN & (PN) & Total \\
\hline Total & 150 & 75 & 70 & 295 \\
\hline
\end{tabular}

The following properties characterize the elements in the three constructions:

\subsection{Subject}

The subject may be explicit or implicit.

\subsection{Verb}

A copular predicate in a main or dependent clause. The copula in its various inflected forms was the most common verb in the sample, but verbs such as seem also qualify and were identified. It turned out that there were so few instances of verbs other than the copula that our analysis can be restricted to true copula forms.

\subsection{Adjective}

For PAs, the adjective is in predicative position and for PANs the adjective is attributive, modifying the noun.

This criterion requires a determination of what is an adjective. Setting aside determiners for the moment, most of the noun modifiers in the data fit the intuitive definition of adjective-words such as good, difficult, or funny. The adjectives in the PAs are almost all gradable adjectives, with only a few that simply name a category, such as Brazilian or pregnant. We included Past Participle forms, such as concerned or freaked out, and Present Participles, such as frustrating or time-consuming.

Some noun modifiers have special distributional properties, e.g., ordinal numerals, as in my first child, and the word same. These modifiers have functions distinguishable from the more prototypical adjectives, as do the very few cardinal numbers found in our data, such as in 800 in 800 dollars or 160 in $160 \mathrm{~km}$. Thus we chose not to include cardinal and ordinal numerals and the word same in our analysis. ${ }^{5}$

\subsection{Other Elements}

These constructions may be augmented in various ways, including, for example, with intensifiers modifying the adjective (like real, total), auxiliaries (like could be, might be), hedges (like sort of, kind of), turn-initial particles (like so, but, and, I think), and quotatives (like she's like, he goes). Constructions that met the other criteria and included these types of additional elements were included in the data set.

We omitted formulaic greetings such as How are you? and their responses, and instances where a phrase was repeated verbatim within a single interchange.

As for PNs, they were identified as having a noun phrase (without an adjective) as complement to the copula.

We coded the data for a number of properties; those that turned out to be relevant for the claims in this paper are:

a. Whether or not the Predicate Copular Construction is a prosodic unit and/or a turn in the interaction (cf. Section 5)

b. Whether the Copular Predicate Construction is interactionally serving to inform, assess, or both (cf. Section 6)

c. Whether the subject is a full NP or a pronoun and the nature of that pronoun (cf. Section 7)

d. Whether the NP in the PAN or PN is definite or indefinite (cf. Section 8)

e. Whether the subject is a person, or an entity, a situation, or an activity (cf. Section 9.1). 


\section{Distribution of PAs and PANs}

As noted above, PAs are much more frequent in conversation than PANs. In the five conversations from CALLFRIEND that were coded for both PAs and PANs, there were almost six PAs for every PAN. In the study reported on in Bybee and Napoleão de Souza (2019), 100 tokens each of 10 adjectives were selected from the Switchboard corpus and coded for occurrence in attributive or predicative constructions. In that sample, there were also six PAs for every one PAN. Even though PANs are less frequent, they constitute an important use of attributive adjectives. In the study just cited, around one-third of attributive adjectives occur in a PAN. Thus, even in the attributive function, adjectives can participate in predication. Exactly how adjectives function in PANs is one of the main foci of this article.

\section{How Do PAs and PANs Function?}

As we examined the data, it became clear that the work that the PAs and PANs do can be understood at two different levels, one more semantic and cognitive, the other more pragmatic and dialogic. At the more semantic level, PAs ascribe a property to a subject referent, as in (4), while PANs, like all PNs, may either place the subject referent into a category, as in (5) or equate the subject referent with another nominal, as in (6).

(4) PA I was miserable

(5) PAN it was atypical weather

(6) PAN that would really be the right price

At the more pragmatic level, PAs and PANs serve as either assessments and/or informings. We will discuss these functions further in Section 6 .

\section{Copular Predicative Constructions and Turn-Taking: PAs and PANs as Turn Constructional Units}

A striking finding revealed by our data is the clear role that PAs and PANs play in building a conversational turn. Nearly all PAs and PANs form prosodic units of their own ( $71 \%$ of PAs and $91 \%$ of PANs), and of these, many are turns in and of themselves, as in the boldfaced lines in (7)-(9):

(7)

Justin: hhh so: that mea:ns you don't hav:e to pa:y anymor:e

Steve: ri:ght, yea:h, I'm all don:e.

Justin: (0.3) that's good

(8) [Nick is telling about a career-planning course he took]

Nick: like in the- they had mock interviews they all - they had us on ca:mera they showed it to the whole cla:ss

Sam: oh [really

Nick: $\quad$ [hhh hhh

Sam: so $\mathrm{xxx}$ school is

Nick: yeah it was a good class,

Sam: doing the mistakes you mean.

Nick: yeah.

(9)

Ros: oh: and that's quite a drive from here too:

hhh well you know eh seven days a week is just too much for me, I

can't 'do it with (.) children. hh and as 'you say if I: c'd find

some(body) to re^lieve me on the weekend

Bea: $\quad \mathrm{mm}-\mathrm{hm}$ ?

Ros: but that's the trouble.

Bea: yeah. $(0.3)$ 
If we assume with Schegloff $(1996 a, 2001)$ that grammatical units have emerged from the exigencies of social interaction, and that "units such as the clause, sentence, turn, utterance, ... all are in principle interactional units" (emphasis original) (Schegloff 2001, p. 235), then grammatical constructions, such as clauses, can be understood as interactional practices, emergent products of sedimented and shared routines for resolving recurrent communicative problems, such as giving advice, assessing and informing about people and situations, telling stories, making offers, requesting objects and information, etc. (cf. Thompson 2019; Thompson and Couper-Kuhlen 2005).

In the following we present an analysis of Copular Predicate Constructions in their conversational contexts with the goal of identifying the role they play in interaction, starting with the role the whole construction plays, and continuing to the effects of the different constituents of the construction on the interactional work of the constructions.

\section{Interactional Work of PA and PAN}

As noted above, we analyze PAs and PANs as functioning at two levels: a semantic, more cognitive level and a pragmatic, more interactional level. We propose that for any given instance, both participants and analysts can discern functions at both levels at once. For example, in (9), just above, when Nick says that was a good class, Sam can understand him to semantically be placing his experience in the category of 'good class' and pragmatically to be assessing the experience positively.

To further understand the pragmatic level - the interactional work of PAs and PANswe draw on research in conversation analysis focusing on the routinized social actions that humans use language to accomplish. Levinson (2013, p. 107) characterizes these actions as the 'main job' that a given turn in an interaction is taken by the participants to be performing. Some of these actions are typically relatively straightforward for both participants and analysts to discern, such as greetings, compliments, and invitations, and the ways in which recipients typically respond to them is also relatively routinized ${ }^{6}$ (cf. Schegloff 2007). Other actions are more difficult to pin down among participants and analysts. For example, in a given sequential position, a given turn can be understood by participants, and analyzed by researchers, as either a piece of news or a warning, or both, or an interrogative in a specific position may be treated by participants as either a request for information or as an offer.

Our data on PAs and PANs suggest two actions that they are generally used to implement:

a) giving a subjective evaluation or assessing (Goodwin 1986; Goodwin and Goodwin 1987, 1992; Lindström and Mondada 2009; Pomerantz 1984), as in:

(10) five dollars a week is ridiculous.

(11) they're too dumb

(12) (so it) was a little intense this mo(h)rning?.hh

(13) she's a ma:sterful wri:ter

(14) this is a big fucking fish

[PAN]

b) providing information or informing (Mori 2006; Thompson et al. 2015; Vatanen 2018), as in:

(15) I was half asleep

(16) she's Brazilian

(17) yeah, it's a true story 
Because adjectives are relative and gradable, it is sometimes difficult, again, for both those in the interaction and those analyzing it, to distinguish between informing and assessing. For example, expensive in (18), informs the recipient about the price of shoes, but expensive is a relative term which can differ in interpretation according to the individual's stance and frame of reference, thus making it a subjective assessment while still being informative.

In another sort of situation, a woman reporting on her experience during pregnancy utters (19), which could be taken as both an informing-a report on how things have been going - and an assessment-her subjective reaction to the situation.

A small majority of PAs and of PANs are assessments (53\%), and informings make up around $38 \%$, with the remainder doing both kinds of work. In contrast, the PNs play an informing role in about $80 \%$ of cases. This difference between the constructions with and without an adjective suggests that the adjective plays a significant part in the work of assessing, and we will see in Section 8 that this is indeed the case.

\section{Subjects of the Copular Predicate Constructions}

In our data, for the PA and PAN constructions, as well as for the PN constructions, the majority of subjects are third person singular pronouns, particularly the inanimate pronouns it, that and this, in accord with findings of studies that include all types of predicates (Scheibman 2002) (see Table 2). A firm conclusion is that Copular Predicate Constructions are used most commonly, at least by English speakers, to discuss known entities and situations. Additionally, in accordance with previous studies of conversational data, full NP subjects are much less frequent than pronouns, occurring in only $5 \%$ of the examples (Chafe 1994; Givón 1983; Fox 1987; Du Bois 1987).

Table 2. Inanimate pronoun subjects found in PA, PAN and PN constructions.

\begin{tabular}{ccccc}
\hline & PA & PAN & PN & Total \\
\hline it & 37 & 31 & 26 & 94 \\
\hline that & 34 & 15 & 15 & 64 \\
\hline this & 7 & 6 & 7 & $178(60 \%$ of all subjects, $76 \%$ of all pronoun subjects $)$ \\
\hline total & & & &
\end{tabular}

The trends in pronominal usage are the result of the interactional functions of PAs and PANs. The most frequent pronouns are it and that. A difference in their usage emerges in a frequently used conversational structure in the data: the telling of a story or the construction of a situation by one speaker, whom we'll designate as S1. If this speaker is initiating a comment or an assessment on a situation, s/he may use a PA or PAN, which in effect guides the recipient's reaction to the situation, in which case the pronoun it is usually used, as in (40). When a recipient (S2) reacts to the comment in the form of a PA or PAN, that is more commonly used than it, as in (21):

(20) I mean I'm glad I got into schoo:I (.) it's a nice o:ption

(21) Justin: they all look like tha:t. and [they ha:ve ]n't cha:ng:ed since eightee:n (0.3) [f:if: [ty eigh:t]

Steve: [yea: :h ] 
equal numbers to do informing or assessing. However, when S2s use a PA or a PAN, they use them $85 \%$ of the time to do assessments. That is, S1, the speaker creating the situation, uses PAs and PANs as part of their telling, but the recipient, S2, usually provides reactions in the form of assessments, referring to the situation that $\mathrm{S} 1$ has described.

From speakers' use of it and that, we also see that those who have the floor conceptualize situations differently from those who do not: if I have the floor, as in (40), I will use the neutral pronoun it to refer to the situation I am telling you about, which is in my epistemic territory (Raymond and Heritage 2006; Kamio 1997). If I do not have the floor, as in (21), and I am responding to 'your' situation, I am likely to use the markedly distal pronoun that.

The subjects of PA and PAN constructions reveal two key aspects of the work that speakers draw on these constructions to do; first, while speakers indeed tend to talk about themselves and other humans, a strong trend is to use a PA or PAN construction to assess situations. Second, these constructions are drawn on differently depending on whether the speaker is the primary teller or the recipient.

\section{Definite and Indefinite PANs and PNs}

PANs are more complex than PAs, as their predicates include a noun and thus constitute a full NP. In English, of course, this means that they often have a determiner as well, which can be either definite or indefinite. Naturally, the same is true for the PNs. As we will see, the definiteness of both PANs and PNs is closely interwoven with their interactional function: the semantic function of categorizing is nearly always done with an indefinite Predicate NP, while the semantic function of equating is nearly always done with a definite Predicate NP.

\subsection{Categorizing and Indefinite Predicate NP}

In Predicate NPs both with and without an adjective (PNs and PANs), indefinites are far more frequent than definites (see Table 3).

Table 3. Definite and indefinite NPs in PNs and PANs.

\begin{tabular}{ccccc}
\hline & PNs & PANs & Total & $\%$ \\
\hline Indefinite & 46 & 64 & 110 & $88 \%$ \\
\hline Definite & 24 & 11 & 35 & $12 \%$ \\
\hline Total & 70 & 75 & 145 & $100 \%$ \\
\hline
\end{tabular}

As noted above, with an indefinite Predicate NP, the PAN clause names the subject referent as a member of a category, as in examples (22)-(28). We also analyze (25) and (26) as categorizing even though the category is subjective and the PAN is interpreted as an assessment.

it's a it's an 0::ld really o:ld Sony Trinitro:n

[talking about a book $\mathrm{RO}$ is reading]

it's written by the granddaughter of it

so it was a ${ }^{\circ}$ true: story $^{\circ}$

yeah

is it bi::g hhh

it's a nineteen-i:nch scree::n

this is a big fucking fish

[talking about why she doesn't need strollers anymore]

they're very heavy and they're really a big pain

and the kids can walk
[PAN]

[PAN]

[PAN]

[PAN]

[PAN] 
In some instances, the noun in a PN or PAN provides an assessment. Our data set contains a small number of such nouns, and these seem to be conventionalized expressions, suggesting that using $\mathrm{P}(\mathrm{A}) \mathrm{Ns}$ to provide assessments is not a productive strategy.

(27)

MAGGIE :

(28)

Ava:

Bee:

Ava:

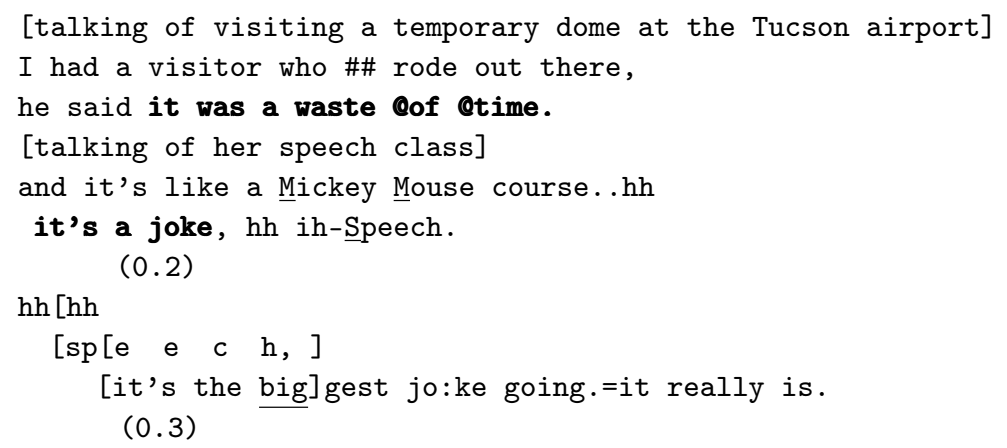

When using PANs to talk about people, there is also a tendency to refer semantically to rather conventional categories, such as a bad person, a better person, a funny guy, or a productive member of society. Pragmatically, these often imply an assessment as well.

When it comes to situations, at the pragmatic level, the assessing function is prominent, though the speaker is still pragmatically assigning the situation to a category, albeit a rather subjective one. Sometimes the assessment is expressed in the noun: a real let-down, a total waste. More often, the adjective supplies most of the assessment meaning: a good thing, a pleasant surprise, a stressful weekend, a nice option. In such cases, the category named by the noun tends to be quite general (see Section 9.1).

One difference, then, between PANs and PNs is that in the former, an assessment may be expressed either in the adjective or the noun. In kind of a dead-end job and a good class the assessment is expressed in the adjective, but in a real let-down and a total waste the assessment is in the noun. In PANs, it is more common for the assessment implication to be carried by the adjective, while the noun is more neutral or informing, as in a nice option and a stressful weekend (see Section 9.1). Thus, even though a PAN is syntactically a predicate nominal, it appears that most of the work of assessing is accomplished by the adjective. This explains the fact that, among PNs, around $80 \%$ are informing, while PANs are more evenly split, tending toward assessment in $53 \%$ of cases, as mentioned above.

\subsection{Definites}

In a definite $\mathrm{PN}$, the clause in general establishes an equivalence, whose function it is to equate one referent with another.

(30) the one that said twenty was the bo- the branch manager.

$[\mathrm{PN}]$

$[\mathrm{PN}]$

As for the social work these clauses are doing, most of them are doing informing; they veer into assessing in a few cases, in which the noun expresses a subjective evaluation, such as that's the trouble. More commonly, as in (29) and (30), for example, PNs are doing their prototypical work of delivering a piece of information from a knowing to an unknowing recipient.

In contrast, there are very few definite PANs in our data, and these are mostly conventionalized assessments, as in the biggest pain in the ass, the funniest thing, and the good news. Thus, the presence of an adjective in a definite PAN strongly correlates with speakers' use of a PAN clause to do assessing. The small number of definite PANs and their use as conventionalized assessments suggest that constructions with definite PANs are not productive. 


\section{The Role of the $\mathrm{N}$ and the $\mathrm{A}$ in These Constructions}

\subsection{The Noun: Comparison of PNs and PANs}

Throughout the discussion, we have seen that the nature of the adjective plays a pivotal role in determining whether the Copular Predicate Construction works to inform or assess.

In fact, the work of assessing or stating a subjective evaluation of the subject falls on the shoulders of the adjective rather than the $\mathrm{N}$ in more than $80 \%$ of our PAN-assessing examples. This fact leads to the question of the role of the $\mathrm{N}$ in a PAN. Our PAN examples fall roughly into four types.

The first type are examples in which the $\mathrm{N}$ is bringing new information to the conversation; as we would expect, these mostly do informing rather than assessing work.

(31)

Justin: (0.7) are doing the so:ft uh uh a:: Be:ll

Nor:thern Research is a sub- seduary7 of

Nor:thern Teleco: :m:

Steve: uh huh

Justin: which i:s: a c- the c- mainn competitor to ATT for:

switching: :

Steve: $\quad$ o:kay
RO:

LI :

RO:

(33)

LI:

RO :

Mir :

Raq:

Mir :

Raq:

Mir :
Here the $\mathrm{N}$ competitor is central to the point that $\mathrm{M} 1$ is making.

In the second group, the $\mathrm{N}$ is fairly specific, but the referent has already been introduced in the conversation, as in (32). [talking about a book]

The Language Instinct

yea:h (.) it's just really [interesting reading] so $y(o u)$ you know

[S $t$ e v e $n$ Pinker ]
[PAN]

This group of adjectives is largely doing assessing. That is, the speaker offers the assessment interesting and could have done this with a PA it's just really interesting, but she adds the $\mathrm{N}$ reading. This $\mathrm{N}$ makes a minimal semantic contribution, but places the experience into a category 'reading', which groups it with other reading, and supports the inference that this book is 'interesting' as a reading experience, rather than, for example, as a reference work or a humor book. Indeed, Liz goes on to comment that a benefit of being at home with one's baby is that she gets to read while her daughter naps.

And a few seconds later, Liz makes this assessment, which illustrates a similar inferencing from a PAN with an already introduced $\mathrm{N}$ :

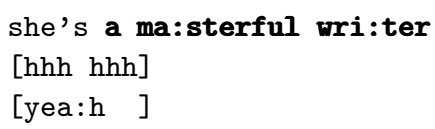

Here Liz could have simply used a PA construction 'she's masterful'. But in adding the $\mathrm{N}$ writer, she places the author into a category of writers; that is, this author is not just 'masterful', but she is masterful as a writer.

The third group uses an empty $\mathrm{N}$ that is highly general, while the A carries the most information. Again, as we might expect, in these cases, the PAN is mostly assessing.

you ought to buy a cradle,

a beautiful cradle

maybe I'll buy a bed for my kids

$(0.9)$

hhh hhh hh $(2)$ the other ki:ds

yea: $h$

hhh that's a good thing 
In the final group, comprising only six examples, the $\mathrm{N}$ itself (plus any intensifiers, as seen in (35)) provides the assessment:

(35)

Ed:

cause I had one from the UI a two years ago a vocational

orientation

Dick: yeah

Ed:

Dick:

yeah George Brown it was a it was a total waste

[PAN]

Ed:

waste

this is a - this is a YMCA

These four types pattern functionally as shown in Table 4.

Table 4. The role of the $\mathrm{N}$ in the PAN.

\begin{tabular}{lccc}
\hline & Informing & Assessing & \\
\hline N adds new info & 17 & 2 & 19 \\
\hline N not new & 8 & 17 & 18 \\
\hline $\begin{array}{l}\text { General N, A carrying } \\
\text { most weight }\end{array}$ & 4 & 14 & 8 \\
\hline N carries most weight & 0 & 8 & \\
\hline total & 29 & 41 & \\
\hline
\end{tabular}

What these data show is that, given that the $\mathrm{N}$ is redundant or highly general in most cases, it is the adjective that is typically driving the interactional function of the PAN in the context. Thus we see a trend in which the choice to use either $\mathrm{N}$ or $\mathrm{A}$, or both, within Copular Predicate Constructions corresponds to certain interactional actions. In PANs and PNs the noun semantically names a category, and is thus pragmatically doing informing, both when it introduces a new categorization and when the category is redundant in context. But the adjective that modifies a redundant or empty $\mathrm{N}$ tends to offer a subjective evaluation, i.e., an assessment, rather than objective information.

This analysis of the roles of Ns and As is supported by the examples of PNs, which lack any adjective, and which accordingly do informing much more frequently $(80 \%)$ than assessing $(20 \%)$.

\subsection{Comparison of PAs and PANs}

In this section, we address the role of the $\mathrm{N}$ by comparing Copular Predicate Constructions that lack an $\mathrm{N}$ with those that include one. There are two major quantitative skewings in our data. The first occurs when the subject of the construction is a person. With a person as subject, about $70 \%$ of the examples are PAs rather than PANs, and these work primarily to inform. They tend to occur when the speaker is describing a temporary state, as in the following examples:

(36)

Steve: $(0.3)^{\circ}$ an: $: d^{\circ}[$ so: $0: n$ so she was not very happy

(37)

Note that such examples contrast with those containing a N, which would put the subject into a category; consider, e.g., the contrast between 'she was not very happy' and 'she was not a very happy person.' The latter would categorize the subject, attributing to it the properties associated with the category, rather than describing a state in which the person happens to be at a point in time. In this case, 'she was not very happy' carries the connotation that unhappiness was a temporary trait of the person, in contrast to 'she was not a happy person', which indicates a relatively long-lasting state. ${ }^{7}$ To support this point, we observe that of 75 PANs, only fourteen have a person as subject. Interactionally, these 
all serve to inform recipients about the semantic category the person belongs to. Here is a further example

(38)

LI: (0.6) he said he thought that sounded like a good idea

$(0.7)$

RO: $\mathrm{m} \mathrm{hm}$

LI :

RO:

(39)

Mom:

(40)

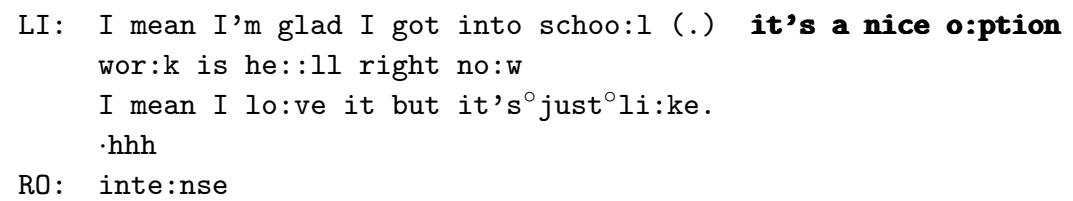

Here, at the semantic level, Mom is identifying the several days surrounding Thanksgiving as the category 'weekend', and, at the pragmatic level, assessing this instance of that category as a stressful one.

In other cases, the $\mathrm{N}$ actually identifies the category that the speaker wants to place the referent in. Consider (40): and are doing informing rather than assessing, as they occur in tellings about oneself or other people.

In the case of subjects that are not people, the difference between PA and PAN is more subtle. In some cases, the N makes the referent clear, as in (39), where Mom is telling daughter Julie how she manages the Thanksgiving weekend while trying to avoid drinking:

[yea:h he] i::s hhh

The data also show that subjects referring to situations, entities, or activities are much 
The Adjective in a PAN can also help to define a category (as in (22), repeated here as (41))

(41) it's a it's an $0:$ :ld really $0: 1 d$ Sony Trinitro:n

[PAN]

but more often it expresses an assessment, a subjective evaluation by the speaker. In this way, the PANs resemble the PA examples in the corpus, many of which are also assessments. The role that the adjective plays tends to depend upon the lexical meaning of the adjective, with adjectives such as stressful, pleasant, nice, good, and bad expressing assessment in most cases.

The results reveal an interesting interplay between the syntactic form of the utterance and its lexical content in determining the work it is doing in conversation. As noted by many researchers (Goldberg 1995, 2006; Boas 2003; Gahl and Garnsey 2004; Bybee and Eddington 2006), lexical items and constructions are strongly associated in cognitive representation. That is, what language users know about lexical items includes not just their meaning, but also the constructions in which they have been experienced. Conversely, knowledge of constructions includes the set of lexical items used in the construction.

Given that cognitive representations are records of previous experience with words and constructions (Bybee 2006), these representations also contain information about the interactional and social contexts in which they have been used. All of this informationlexical meaning, constructional meaning, interactional context-influences the choices the speaker makes about the content of her utterance. These same factors guide the listener in the interpretation of the utterance.

Our analysis suggests that when speakers aiming to accomplish a certain interactional move have made certain lexical choices, the constructions in which those lexical items occur become available, and one of those constructions is then employed. With respect to adjectives, some have been found to occur more often in predicative position while others occur more often in attributive position (Huddleston and Pullum 2002; Boyd and Goldberg 2011; Bybee and Napoleão de Souza 2019). For example, Boyd and Goldberg study a set of English adjectives with an $a$-prefix, such as asleep and afraid, which only occur predicatively. In the data analyzed in Bybee and Napoleão de Souza 2019, the English adjective sad occurs predicatively about $80 \%$ of the time, while red occurs predicatively only about $10 \%$ of the time. In addition to these syntactic usage tendencies, constructions also have pragmatic and interactional histories registered with them. Given this detailed knowledge about constructions, pragmatics, and interaction, we suggest that, for example, the choice of the adjective weird as an assessment could lead directly to the utterance it's/that's weird, using a PA, a common construction for weird and an inanimate subject.

The data examined here also underscore the importance of the lexical content of the turns. Given that the speaker's choice of words to inform or assess may be a major determinant of the construction chosen, certain interactional structures may also trigger the combined choice of lexical item and construction. ${ }^{8}$ In particular, we find speakers at times using PAs and PANs to guide recipients in interpreting a described situation, and we find recipients using the same constructions to provide responsive feedback and assessment. The data suggest, then, that in online processing in conversation, speakers are controlling the lexical content of what they want to say, as well as the appropriate syntactic construction and the interactional context, and all of these factors together determine how the turn unfolds.

The pervasive intertwining of lexical, grammatical, and interactional factors in language use leads to questions about the abstractness of syntactic representations. In particular, at the most abstract level, the PN and PAN constructions can be reduced to the same formula, i.e., [SUBJECT + COPULA + NP]; since the NP may contain determiners and adjectives as well as a noun, PNs and PANs are thus both Predicate Nominals. Yet the data show major differences in contexts of use: PNs are largely used for informing, while PANs are more often used for assessing (see Table 4). This suggests that, given the importance of the lexical adjective in determining the role of the PAN and PA in interaction, PANs are 
more similar in usage to PAs than to PNs, in opposition to the conclusion one would reach based just on their syntax.

Another argument for separate PAN and PN constructions is as follows: If language users have knowledge of prior use of constructions, this information has to be linked to the construction in cognitive representation. If PNs and PANs have different contexts of use, then there has to be a PAN construction to which specific information may be attributed that is perhaps not applicable to PNs. Similarly, since PNs, lacking an A, have a specific set of uses, this information has to be linked to a construction lacking an A. As pointed out in the construction-grammar literature (see Bybee 2006 and Goldberg 2006 and others), specific instances of constructions may develop special meanings or implications, which has the effect of establishing a new construction in cognitive representation. For example, the conventionalized expressions we mentioned before-the biggest pain in the ass, the funniest thing, the good news and the nice thing - which use the definite article, have idiosyncrasies of meaning that make any generalizations on the role of the definite article difficult. Thus the meaning and appropriate contexts of use of such expressions have to be learned and stored as if they were separate constructions. What our analysis adds is that even interactional uses of constructions constitute part of the linguistic knowledge that guides constructional choice.

Observing language use in conversation, it is difficult to discern whether the more abstract knowledge that has traditionally attracted the interest of linguists, that is, generalizations such as [SUBJECT + COPULA + NP], which would cover both PNs and PANs, is a representation useful to speakers. While it is generally accepted that human language users are capable of finding patterns in their linguistic experience, it is still difficult to find empirical evidence for highly abstract constructions, given that the use of analogy based on known exemplars of experience can also account for the productivity found in language use (Skousen 1989; Boas 2003; Krott et al. 2001; Bybee and Eddington 2006; Bybee 2010, among others). Perhaps, the constructions we have examined here-PA, PAN and PN—can be usefully considered a family of constructions in the sense of Goldberg and Jackendoff (2004).

In terms of the aims of this Special Issue, asking what is the correspondence between linguistic categories established based on structural considerations and their use in interaction, we note first that the Predicate Copular Constructions have a strong tendency to comprise a turn in conversation. In cases where these constructions occur in a longer stretch of talk, they still comprise a prosodic unit. This correspondence between prosodic structure and syntax provides evidence for the cognitive reality of the specific constructions, as well as a means for such constructions to emerge from usage. But we also noted that each of these proposed constructions functions a little differently. PNs seem to correspond to a narrow range of interactional work - that of informing through the use of categorization. In contrast, both PAs and PANs, though they are structurally different, can be used for both informing and assessing, depending upon the nature of the A, the presence or absence of a $\mathrm{N}$, and the context of use. Thus, we find evidence for constructions in interaction, but at a less abstract level of generalization than one would propose from a syntactic point of view.

Finally, as linguists interested in finding the interactional roots of linguistic structure, we note some of the broader implications.

1. Attributive vs. predicate adjectives. First, we note first research comparing adjectives across registers in English. Englebretson (1997) shows how the frequency of predicative vs. attributive adjectives is related to aspects of the interactional environment; specifically, he argues, a proportionally greater number of predicative adjectives are found when the participants "are discussing referents which are shared background knowledge", while a greater number of attributive adjectives occur when participants "are introducing new referents which are not shared knowledge" (418).

Englebretson's results are entirely compatible with the findings of Biber et al. (1999, pp. 506ff), who compare the following four registers of English discourse: spoken telephone conversation, written fiction, written news, and written academic. Intriguingly, they find that in conversation, 
a. there are fewer adjectives than in the other genres,

b. those few adjectives are distributed about evenly across attributive and predicative uses. $^{9}$

In contrast, in all three written corpora,

a. many more adjectives are used

b. attributive adjectives far outnumber predicative uses

Furthermore, our data show that predicative uses of adjectives typically have just one item of lexical content per clause, while attributive uses, by definition, tend to have more density of content, with two or more units of lexical content per clause. That is, the predicative PAs robustly conform to the 'light subject constraint' (Du Bois 1987; Chafe 1994): they are of the form [Subject pronoun COP Adj], with the PA supplying the only lexical content. The PANs, in contrast, contain both an attributive adjective and a noun, each contributing one piece of lexical content.

These studies suggest, then, that the greater use of adjectives, especially attributive adjectives, is related to the greater lexical density that arises where the planning of formal speech or written language is possible. It may be that diachronically, adjective use and an attendant increase in the size of adjectival lexicons, increased with the rise and spread of writing in a culture.

2. PANs: attributive or predicative constructions? At the outset of this article, we raised the question of whether the $\mathrm{A}$ in a PAN construction is doing the work of an attributive, or a predicative, adjective. The facts we have presented here show that the $\mathrm{A}$ in a PAN construction, though it fits a strictly syntagmatic definition of 'attributive' by being pre-nominal, is playing the functional role of a predicative adjective. This is due to the fact that adjectives are used far more frequently for assessing than are nouns, and PANs are used interactionally to do more assessing work than PNs, which have no adjective. Thus, even though a PAN is syntactically a predicate nominal, with a grammatically attributive adjective, it appears that most of the work of assessing is accomplished by the adjective.

3. Languages with and without a lexical category of 'adjective'. Dixon (Dixon [1970] 2010) argues that the lexical category 'adjective' tends to express a constant set of semantic concepts in languages that have such a category. He also shows the variety of ways that languages with no such lexical category express these 'adjectival concepts'. Following his lead, Thompson (1988) discusses three types of languages with respect to such semantic 'property concepts': those in which a distinct lexical category of 'adjective' can be justified on distributional grounds, those in which property concepts pattern morphosyntactically like verbs, and those in which property concepts pattern morphosyntactically like nouns. As more studies are carried out with a wider range of languages, we anticipate that this distinction might be linked to differences in adjective use across these three language types. We suggest further that interactional functions such as informing and assessing could be tied to these differences in lexical categorization. We hope to see further research devoted to the pursuit of such issues for a rich variety of languages.

Author Contributions: Both authors have contributed equally to the research and writing of this paper. All authors have read and agreed to the published version of the manuscript.

Funding: This research received no external funding.

Institutional Review Board Statement: The recorded data for this study were approved for our use many years ago by the UCSB Office of Research Human Subjects Committee, which serves as the Institutional Review Board (IRB) for reviewing research applications involving human subjects.

Informed Consent Statement: Informed consent was obtained from all subjects involved in the study.

Data Availability Statement: In the text of the paper.

Conflicts of Interest: The authors declare no conflict of interest. 


\section{Appendix A. Transcription Conventions}

\begin{tabular}{|c|c|}
\hline : & prosodic length \\
\hline $\mathrm{a}$ & accented syllable \\
\hline (h) & laughter within a turn \\
\hline .hh & inbreath \\
\hline hhh & outbreath \\
\hline [ ] & overlap \\
\hline$?$ & rising final intonation \\
\hline- & cut-off \\
\hline$x x x$ & uncertain hearing \\
\hline$(1.2)$ & pause, timed \\
\hline$=$ & one turn unit latched to another \\
\hline$\circ$ & low volume \\
\hline (.) & short pause \\
\hline 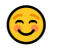 & laughing voice \\
\hline
\end{tabular}

\section{Notes}

1 When we say 'PAN' or 'PN', we include 'Ns' accompanied by determiners and/or non-adjectival modifiers, as in these examples from our data:

(i) she's a pain in the ass [PN]
(ii) it's the smell of fish

We also include PAs whose adjective was followed by a complement, as in:

(iii) well it's weird for me to work, the counter by myself

(iv) I'm pretty su:re that my woman friends would agree.

All examples are from our conversational data unless marked otherwise.

For transcription conventions, please see the Appendix A.

https:/ / catalog.ldc.upenn.edu/LDC96S46 (accessed on 17 August 2020).

5 We also encountered a handful of interrogative Copular Predicate Constructions in the data, but determined that their interactional functions are different enough from declarative Copular Predicate Constructions to warrant excluding them for this study.

6 There is an extensive body of research in this area; for an overview, see Clift (2016); Couper-Kuhlen and Selting (2018); Sidnell (2017); Sidnell and Stivers (2013) and Schegloff (2007).

7 It is well-known that Spanish has distinct verbs, ser and estar, for this 'essential' vs. 'accidental' distinction in Copular Predicate Constructions (see Clements 2006 for a data-based study of this distinction).

8 We note that this is in stark contrast to competence models of syntax, which model speakers as generating a skeletal syntactic structure prior to choosing lexical items.

9 Thompson (1988) and Bybee and Napoleão de Souza (2019), however, both studying mundane conversational language, independently find that predicate adjectives far outnumber attributive adjectives. Englebretson's study suggests that this discrepancy is likely to be largely due to interactional register: the more formal the register, the fewer the shared referents, and the greater the percentage of attributive adjectives.

\section{References}

Biber, Douglas, Stig Johansson, Geoffrey Leech, Susan Conrad, and Edward Finegan. 1999. Longman Grammar of Spoken and Written English. London: Longman.

Boas, Hans. 2003. A Constructional Approach to Resultatives. Stanford Monographs in Linguistics. Stanford: CSLI Publications.

Boyd, Jeremy K., and Adele E. Goldberg. 2011. Learning What Not to Say: The Role of Statistical Pre-emption and Categorization in a-adjective Production. Language 87: 55-83. [CrossRef]

Bybee, Joan. 2006. From Usage to Grammar: The Mind's Response to Repetition. Language 82: 711-33. [CrossRef]

Bybee, Joan. 2010. Language, Usage and Cognition. Cambridge: Cambridge University Press.

Bybee, Joan, and David Eddington. 2006. A Usage-Based Approach to Spanish Verbs of "becoming". Language 82: 323-55. [CrossRef] Bybee, Joan, and Ricardo Napoleão de Souza. 2019. Vowel Duration in English Adjectives in Attributive and Predicative Constructions. Language and Cognition 11: 555-81. [CrossRef]

Chafe, Wallace. 1994. Discourse, Consciousness, and Time: The Flow and Displacement of Conscious Experience in Speaking and Writing. Chicago: University of Chicago Press.

Clements, J. Clancy. 2006. Ser-estar in the Predicate Adjective Construction. In Functional Approaches to Spanish Syntax. Edited by J. Clancy Clements and Jiyoung Yoon. London: Palgrave MacMillan, pp. 161-202. 
Clift, Rebecca. 2016. Conversation Analysis. Cambridge: Cambridge University Press.

Couper-Kuhlen, Elizabeth, and Margret Selting. 2018. Interactional Linguistics: Studying Language in Social Interaction. Cambridge: Cambridge University Press.

Dixon, R. M. W. 2010. Where Have All the Adjectives Gone? In Where Have All the Adjectives Gone?, and Other Essays in Semantics and Syntax. Edited by R. M. W. Dixon. Berlin: de Gruyter, pp. 1-61. First published in 1970.

Du Bois, John W. 1987. The Discourse Basis of Ergativity. Language 63: 805-55. [CrossRef]

Englebretson, Robert. 1997. Genre and Grammar: Predicative and Attributive Adjectives in Spoken English. Proceedings of the Berkeley Linguistics Society 23: 411-21. [CrossRef]

Fox, Barbara A. 1987. Anaphora and the Structure of Discourse. Cambridge: Cambridge University Press.

Gahl, Susanne, and Susan M. Garnsey. 2004. Knowledge of grammar, knowledge of usage: Syntactic probabilities affect pronunciation variation. Language 80: 748-75. [CrossRef]

Givón, Talmy. 1983. Topic Continuity in Discourse: A Quantitative Cross Language Study. Amsterdam: Benjamins.

Goldberg, Adele. 1995. Constructions: A Construction Grammar Approach to Argument Structure. Chicago: University of Chicago Press.

Goldberg, Adele. 2006. Constructions at Work. The Nature of Generalization in Language. Oxford: Oxford University Press.

Goldberg, Adele, and Ray Jackendoff. 2004. The English Resultative as a Family of Constructions. Language 80: 532-68. [CrossRef]

Goodwin, Charles. 1986. Between and within: Alternative treatments of continuers and assessments. Human Studies 9: 205-217. [CrossRef]

Goodwin, Charles, and Marjorie H. Goodwin. 1987. Concurrent Operations on Talk: Notes on the Interactive Organization of Assessments. IPRA Papers in Pragmatics 1: 1-54. [CrossRef]

Goodwin, Charles, and Marjorie H. Goodwin. 1992. Assessments and the Construction of Context. In Rethinking Context. Edited by Charles Goodwin and Alessandro Duranti. Cambridge: Cambridge University Press, pp. 147-89.

Hengeveld, Kees. 1992. Non-Verbal Predication: Theory, Typology and Diachrony. Berlin: Mouton de Gruyter.

Huddleston, Rodney, and Geoffrey K. Pullum. 2002. The Cambridge Grammar of the English Language. Cambridge: Cambridge University Press.

Kamio, Akio. 1997. Territory of Information. Amsterdam: John Benjamins.

Krott, Andrea, R. Harald Baayen, and Robert Schreuder. 2001. Analogy in Morphology: Modeling the Choice of Linking Morphemes in Dutch. Linguistics 39: 51-93. [CrossRef]

Levinson, Stephen C. 2013. Action formation and ascription. In Handbook of Conversation Analysis. Edited by Jack Sidnell and Tanya Stivers. Malden: Wiley-Blackwell, pp. 103-30.

Lindström, Anna, and Lorenza Mondada. 2009. Assessments in Social Interaction: Introduction to the Special Issue. Research on Language and Social Interaction 42: 299-308. [CrossRef]

Mori, Junko. 2006. The workings of the Japanese token hee in informing sequences: An analysis of sequential context, turn shape, and prosody. Journal of Pragmatics 38: 1175-1205. [CrossRef]

Narahara, Tomiko. 2002. The Japanese Copula: Forms and Functions. Houndmills: Palgrave.

Ono, Tsuyoshi, and Sandra A. Thompson. 2009. Fixedness in Japanese Adjectives in Conversation: Toward a New Understanding of a Lexical (Part-of-Speech) Category. In Formulaic Language. Edited by Roberta Corrigan, Edith Moravcsik, Hamid Ouali and Kathleen Wheatley. Amsterdam: Benjamins, pp. 117-45.

Overall, Simon E., Rosa Vallejos, and Spike Gildea, eds. 2018. Nonverbal Predication in Amazonian Languages. Amsterdam: Benjamins.

Pomerantz, Anita. 1984. Agreeing and disagreeing with assessments: Some features found in preferred/dispreferred turn shapes. In Structures of Social Action: Studies in Conversation Analysis. Edited by J.M. Atkinson and J. Heritage. Cambridge: Cambridge University Press, pp. 57-101.

Quirk, Randolph, Sidney Greenbaum, Geoffrey Leech, and Jan Svartvik, eds. 1985. A Comprehensive Grammar of the English Language. London: Longman.

Raymond, Geoffrey, and John Heritage. 2006. The Epistemics of Social Relations: Owning Grandchildren. Language in Society 35: 677-705. [CrossRef]

Schegloff, Emanuel A. 1996a. Issues of Relevance for Discourse Analysis: Contingency in Action, Interaction, and Co-Participation Context. In Discourse Processing: An Interdisciplinary Perspective. Edited by Eduard Hovy and Donia Scott. Heidelberg: Springer, pp. 3-35.

Schegloff, Emanuel A. 1996b. Turn Organization: One Direction for Inquiry into Grammar and Interaction. In Interaction and Grammar. Edited by Elinor Ochs, Emanuel A. Schegloff and Sandra A. Thompson. Cambridge: Cambridge University Press, pp. 52-133.

Schegloff, Emanuel A. 2001. Discourse as an Interactional Achievement III: The Omnirelevance of Action. In The Handbook of Discourse Analysis. Edited by Deborah Schiffrin, Deborah Tannen and Heidi E. Hamilton. Oxford: Blackwell, pp. 229-49.

Schegloff, Emanuel A. 2007. Sequence Organization. Cambridge: Cambridge University Press.

Scheibman, Joanne. 2002. Point of View and Grammar: Structural Patterns of Subjectivity in American English Conversation. Amsterdam and Philadelphia: John Benjamins.

Sidnell, Jack. 2017. Action in interaction is conduct under a description. Language in Society 46: 3. [CrossRef]

Sidnell, Jack, and Tanya Stivers, eds. 2013. Handbook of Conversation Analysis. Cambridge: Cambridge University Press.

Skousen, Royal. 1989. Analogical Modeling of Language. Dordrecht: Kluwer Academic Publishers. 
Thompson, Sandra A. 1988. A Discourse Approach to the Cross-linguistic Category 'adjective'. In Explanations for Language Universal. Edited by John Hawkins. Oxford: Blackwell, pp. 167-85, Also in Linguistic Categorization (1989). Edited by Roberta Corrigan, Fred Eckman, and Michael Noonan. Amsterdam: John Benjamins, pp. 245-65.

Thompson, Sandra A. 2019. Understanding 'clause' as an emergent 'unit' in everyday conversation. In Usage-Based and Typological Approaches to Linguistic Units. Edited by Ono Tsuyoshi, Ritva Laury and Ryoko Suzuki. Amsterdam: Benjamins, pp. 11-37.

Thompson, Sandra A., and Elizabeth Couper-Kuhlen. 2005. The clause as a locus of grammar and interaction. Discourse Studies 7: 481-505. [CrossRef]

Thompson, Sandra A., and Hongyin Tao. 2010. Conversation, Grammar, and Fixedness: Adjectives in Mandarin Revisited. Chinese Language and Discourse 1: 3-30. [CrossRef]

Thompson, Sandra A., Elizabeth Couper-Kuhlen, and Barbara A. Fox. 2015. Grammar in Everyday Talk: Building Responsive Actions. Cambridge: Cambridge University Press.

Vatanen, Anna. 2018. Responding in Early Overlap: Recognitional Onsets in Assertion Sequences. Research on Language and Social Interaction 51: 107-26. [CrossRef] 